\title{
Correction
}

\section{Prescribing medicinal cannabis [Correction]}

Aust Prescr 2020;43:225

First published 9 October 2020

https://doi.org/10.18773/austprescr.2020.073

The Table in the medicinal cannabis article by Jonathon Arnold et al. (Aust Prescr 2020;43:152-9) has been amended to clarify Queensland's requirements for prescribing Schedule 8 medicinal cannabis products. View corrected article.

In the 'Documents required' section of the Table, the QLD State Health application cell should have read "No - unless a drug-dependent person" (not "Done simultaneously via TGA online portal").

\section{EDITORIAL OFFICE}

For general correspondence such as Letters to the Editor, contact the Editor.

\section{Postal The Editor}

Australian Prescriber

GPO Box 266

Canberra, ACT 2600

Telephone +61282178700

Email info@australianprescriber.com

Website nps.org.au/australian-prescriber

Twitter@AustPrescriber

\section{SUBSCRIPTIONS}

Australian Prescriber is published every two months online. All content is accessible free of charge in full text at nps.org.au/ australian-prescriber. New drugs are published between issues as they become available.

An email alert can be sent to you when Australian Prescriber publishes new material. Subscribe or update your details at nps.org.au/australian-prescriber

For free copies of the Anaphylaxis wallchart and Switching-antidepressants poster, order online at www.nps.org.au/order\#for-health-professionals
ANSWERS

TO SELF-TEST QUESTIONS

1 False 2 False (c) 2020 NPS MedicineWise ABN 61082034393

NPS MedicineWise Disclaimer Reasonable care is taken to provide accurate information at the time of creation. This information is not intended as a substitute for medical advice and should not be exclusively relied on to

manage or diagnose a medical condition. NPS MedicineWise disclaims all liability (including for negligence) for any loss, damage or injury resulting from reliance on or use of this information. 